\title{
Food versus fuel: the case of the Makeni community in Sierra Leone
}

\author{
A. Wedin, M. Lundgren, C. Mushi, L. Suleiman \& J.-E. Gustafsson \\ School of Architecture and the Built Environment, \\ The Royal Institute of Technology in Stockholm, Sweden
}

\begin{abstract}
Food security can be defined in terms of availability, access, and use of food. The study assesses whether the measures taken by Addax Bioenergy in the Makeni community in Sierra Leone are effective and sufficient to ensure food security locally as well as regionally. Land and water availability, agricultural intensification and infrastructure, self-sufficiency/market dependency and alternative income options have been identified as the main factors affecting food security in the project area. The main measures employed by Addax involve the use of an 'environmental, social and health impact assessment' (ESHIA) to identify and propose measures to mitigate any impacts that would adversely affect the food security of the region. The results show that the proposed measures for mitigating negative impacts on food security are in some instances inappropriate and inadequate, leaving the affected communities exposed to risks and shocks of food insecurity. It is also found that the insufficiency of mitigation measures is a result of weak governance and lack of oversight that may leave the community at the mercy of Addax Bioenergy.

Keywords: food security, impact assessment, Sierra Leone, Addax biofuel project, local community, land sufficiency, agriculture.
\end{abstract}

\section{Introduction}

Surging oil prices and concerns about climate change have led to the search for alternative and more sustainable energy options. Among these options is biomass based energy, so called biofuels. This has led to an increased demand for feed crops for production of ethanol and biodiesel. In turn, eyes have turned to areas that have large amounts of cheap available land for agriculture with suitable 
climates, primarily in developing countries. As the production of biofuels increases, policy makers, lenders and civil society alike are raising concerns over imminent competition between land for food crops and fuel crops (WWI [1]).

In many developing countries governments lease land to an increasing amount of foreign multi-nationals with the hope of enhancing domestic infrastructure, diversifying income opportunities, increasing foreign direct investments and spurring technological advancement. In striking a balance between actor profits, crucial environmental, social and health aspects need to be considered in order not to compromise basic needs and opportunities of the local population. In order to achieve this, precautionary measures and identification of adverse impacts are crucial. One way to achieve the latter is to conduct an environmental, social and health impacts assessment (ESHIA) (WWI [1]).

The Addax biofuel project in the Makeni community in Sierra Leone is one of many biofuel projects currently being implemented in Africa and other developing regions. The project is located in a food production zone crucial for regional and local food security. Addax is said to exercise one of the most ambitious due diligence procedures of its kind assisted by an ESHIA. The main objective of this study is to assess the adequacy and effectiveness of measures taken by Addax to maintain/improve local and regional food security. In order to achieve this objective, the following sub-questions will be addressed:

- What factors affect local/regional food security within the Addax biofuel project?

- What measures were taken to maintain and improve local and regional food security?

- $\quad$ Are the above measures effective and sufficient?

\section{Background}

\subsection{Sierra Leone}

Sierra Leone is located on the western coast of Africa and is considered one of the least developed countries in the world. The Country came out of a civil war in 2002 leaving behind it a shattered country in every sense. Progress has been made in the resettlement of displaced people alongside infrastructural reconstruction and livelihood recovery. Since the end of the conflict, agricultural production has been resumed and the food production is developing steadily. According the World Food Program (WFP) [2], rice outputs represented 80\% of Sierra Leone's total food grain production (based on data collected in 2010) and has been the driving force for food recovery in the country. Even though the rice production has increased threefold since the war, production rates are far beneath potential and not enough to sustain the domestic population on a yearly basis.

One of the main producers of rice is the Makeni area where the Addax project is located. Price fluctuation of imported and locally produced rice is prevalent due to poor road infrastructure, market volatility and an unreliable energy sector with unstable energy prices. The lack of storage capacity and low demand during 
production season brings the price down of locally produced rice. The surplus rice is sold at a cheap price (cheaper than imported rice) immediately after harvest season and decreases as the lean season approaches and imported rice supplies enter the Sierra Leone markets. Large rice producers like the Makeni community, sell the surpluses to other parts of the country and the neighboring countries Liberia and Guinea. 94\% of rice farmers cannot rely on their own produce to last during lean season due to the need of disposing of surpluses rather quickly. Rice farmers are thus also reliant on rice imports and the Makeni community is no exception. The Makeni area has repeatedly faced food security problems in the past making the area vulnerable to risks and shocks (WFP [2]).

\subsection{Addax Bioenergy project}

Addax Bioenergy is a division of the Swiss-based energy corporation Addax and Oryx Group. The company is currently implementing a green field integrated agricultural and renewable energy project in Sierra Leone. The project aims to produce fuel ethanol and electricity expected to be fully operational in 2013. The land for the project includes sugarcane fields, an ethanol factory, a power plant, resettlement areas, ecological preservation areas and project related infrastructure (Afdb [3]). The majority of the biofuel project is located in the district of Bombali while a small part is located in the district of Tonkalili. The area is situated between the Makeni highway in the north and the Rokel River in the south (Afdb [3]).

\section{Methodology}

The Addax ESHIA Executive Summary was the main document of focus for this study. It was the most comprehensive undertaking by Addax in promoting a sustainable operation. The full ESHIA version was considered outdated by Addax and their consultant agency and so it was not provided to us. More updated information of concern could only be shared on signing a Memorandum of Understanding (MOU), which was not possible during the study period. However, best practice requires that the summary reflect key baseline information on the community, main adverse impacts that were identified and the mitigation measures that Addax considered most crucial. Therefore, it was taken as an authentic source of information reflecting crucial project details. Due to financial and time limitations we were unable to visit the location and collect first-hand data, and thus our study is primarily based on data from literature and various internet sources. The study used sources of information including Sierra Leones food insecurity report, as well as other independent field studies and monitoring reports from civil society organizations and academic establishments. Information obtained through correspondence with the Addax Bioenergy Deputy Managing Director Jörgen Sandström is also included. 


\section{Conceptual framework}

\subsection{Food security}

The World Health Organization [4] has provided the following definition of food security: "Food security exists when all people, at all times, have physical and economic access to sufficient, safe and nutritious food that meets their dietary needs and food preferences for an active and healthy life”. Food security is built on three pillars:

Food availability: the availability of sufficient quantities of food of appropriate quality, supplied through domestic production or imports.

Access to food: access by individuals to adequate resources (entitlements) for acquiring appropriate foods for a nutritious diet. Entitlements are defined as the set of all commodity bundles over which a person can establish command given the legal, political, economic, and social arrangements of the community in which they live (including traditional rights such as access to common resources).

Food use: utilization of food through adequate diet, clean water, sanitation, and health care to reach a state of nutritional well-being where all physiological needs are met. This brings out the importance of non-food inputs in food security.

National food security is often defined in the context of national food selfreliance where most of the nutritional needs of the population are met from domestically produced food (FAO [5]). However, this is not the only dimension. According to WFP [2], imports from other regions/countries are also legitimate means of meeting food security. This introduces the concept of financial security to access external markets as an indicator of food security.

The FAO usually includes food stability as a fourth parameter of food security which guards against the risk of losing access to food as a consequence of future sudden shocks or other unforeseen conditions (e.g. seasonal food insecurity). Food insecurity measures strive to build resilience within the food system by identifying and mitigating the many risk factors that are the cause of vulnerability within and between local/regional food systems. Factors that impede on food security include any factors that negatively affect available resources for local/regional food acquisition (WFP [2]).

\section{Results}

\subsection{Factors affecting local/regional food security}

Many factors can be identified as crucial for maintaining food security at a local and regional level. In this section, we aim to identify food security factors at a local level and how these factors interact with regional food security. Food availability either depends on food self-sufficiency or means to acquire food sufficiency through the market. In order to facilitate availability, accessibility to agricultural land or the market is crucial. Subsistence agriculture, 
diverse income opportunities, cash crop supply, leasing of land and paid employment facilitates availability and accessibility. The rate of availability and accessibility is what ultimately defines food security levels. The rate of success depends on the many factors that facilitate food acquisition. The factors identified within the project context are: land and water availability, agricultural intensification and infrastructure, self-sufficiency/market dependency and alternative income options. All these factors are interconnected and if one factor is overrepresented or deficient, food security may be put at risk. Food use is also a crucial factor for food security and this will be highlighted in the next section.

\subsubsection{Land and water availability}

Land availability for cultivation is crucial for subsistence farmers as well as access to land for charcoal provision, pastures and collection of wild plants (Dauber et al. [6]). The average cultivated area prior to the project was estimated to 0.4-2ha per household (Afdb [3]). Households were considered to have more lands than they cultivated mainly due to the slash-and-burn shift cultivation that require lands to rest for some years in order to replenish. Land is also left fallow due to the lack of inputs, labor power, tools, and equipment. Another important resource is water. Water stress resulting from large scale mono-cropping, as in the case of Addax's sugarcane production can have far reaching repercussions for the crop yields of surrounding communities. Local communities in the Makeni region depend mainly on ground water but also surface water and seasonal springs. Wells and springs in communities are often strategically located to enable easy collection by all. The main danger to water sources (both ground and surface) in the project area is from the risk of contamination from the use of fertilizer and other agrochemicals. Another danger could also come from the sources falling within the project whereby the land is rendered unusable (WaterLex [7]).

\subsubsection{Agricultural intensification and infrastructure}

Intensification refers to the use of agricultural inputs, techniques, and equipment that increases yields per cultivated unit. According to WFP [2], increasing intensification of agriculture will be necessary to reach domestic rice selfsufficiency levels. When land becomes scarce higher yields per land unit is one of many ways to try to maintain or increase food supplies. This may require costly investments to be made as it uses more inputs and requires specific types of infrastructure. The infrastructure also determines the price of the produce. Volatile fuel costs and poor transportation systems make for unpredictable prices. Lacking storage facilities will also reduce the storage potential that is important to make seasonal produce last throughout the entire year. This may in turn compel farmers to sell their produce right after it has been harvested when abundant produce floods the markets bringing the prices down as supply outstrips demand.

\subsubsection{Self-sufficiency/market dependency and alternative income options}

The potential for farmers to remain food secure and self-sufficient in the region relies on the production amounts of rice and cassava as well as supply of foods 
like roots and tubers. 65\% of all rice-producing households in the region barely produce enough rice to sustain their families throughout the year and only $5.5 \%$ rely on their own early production. Therefore, alternative food crop sources are important for supplementing and diversifying current diets. Seasonally adapted crops and wild plants that can sustain food sufficiency levels during the wet and lean season are crucial. Many households collect wild plants in surrounding community areas. Limited access to these areas may be detrimental for local food security. According to WFP [2], in the absence of local and regional selfsufficiency, people also become more dependent on volatile international markets. Alternative income options and accumulated wealth are crucial factors for accessing sufficient food from the market. Alternative incomes can be provided through employment opportunities and the leasing of land, but it is important that the monetary gains are sufficient to compensate for the livelihood changes as well as land use change that may be forthcoming.

\subsection{Measures undertaken by Addax to ensure/maintain food security}

\subsubsection{Environmental, social and health impact assessment (ESHIA)}

At the beginning of the project, Addax bioenergy conducted an ESHIA study along with several specialist studies. The purpose of these studies was to identify the possible impacts that the project would have on the environment, health and social patterns of the project area (Afdb [3]). With regard to food security, the following main impacts were identified and mitigation measures proposed: Loss/reduced access to agricultural land, the loss or disruption to existing access routes, the potential for community conflict associated with land disputes, the influx of people into the area as well as local and regional decreases in the standard of living at closure of the project. In order to mitigate this, the project proposed a layout that will avoid as far as possible any physical displacement while ensuring that the Addax land selection strategy avoids the lower lying swamp lands which are currently used for rice production by local people.

Furthermore, creation of job opportunities during the operational phase and the return of young people to the area are forthcoming. Stimulation of economic growth in the area is also forthcoming through benefits arising from FDP, expansion of local skills and small business opportunities that will arise because of the project. Mitigation measures include ensuring opportunities for people directly affected by the project through providing assistance with household budgeting and long term sustainable investments and planning. The project will also convert towards a locally oriented labor force by gradual replacement of expatriates through on-the-job training of assistant managers (Afdb [3]).

Risk of soil contamination, potential pollution of surface and ground waters were considered including contamination of aquatic environments by nutrients and pest control as well as physical and cumulative impacts of water extraction from the Rokel River. A number of field design recommendations have been made to minimize runoff. Ongoing monitoring of surface as well as ground water quality and quantity, fish populations and fisheries and abstraction rates will be implemented (Afdb [3]). 


\subsubsection{FDP and FFLS}

As one of the mitigation measures for the loss of land by local communities, Addax created the Farmer Development Program (FDP) to offset the negative impacts to food security in the area. The FDP is used to support households and communities who are directly affected by the project. The FDP also includes a Farmer Field and Life School (FFLS) training component with the objective of ensuring that affected households have sufficient land and agricultural skills to mitigate potential economic displacement. It also aims to support food utilization objectives by training locals in health and sanitation as well as money management related life skills (Afdb [3]). Addax claims that by the end of the year 2012, 2129 ha of rice fields will have been prepared for communities to utilize. To date 50 FFLS schools have been established with a 30 week training program organized by Addax (Jörgen Sandström). All project-affected communities residing within the boundaries of the development are eligible to participate in the FDP.

\subsubsection{Compensation for land}

The people that will lose their land are to be financially compensated, and the exact terms are to be found within the official Land Lease Agreement. Based on the Provinces Lands Act, the land leases are required to be signed with three chiefdom councils in the project area. The rent (US \$3.60 per acre per year stated in the lease) will be paid to the Chief Administrative Officer and split into four parts: $20 \%$ to the District Council, 20\% to the Chiefdom Administrator, $10 \%$ to the National Government, and 50\% to the land users of the leased area (Jörgen Sandström). Since the traditional tenants are not an official party in land leases, they could not get the payment directly. To respond to this, besides complying with the law, Addax has also negotiated directly with the tenants and the communities who are represented by a law firm chosen by the chiefdom councils, Franklyn Kargbo and Co. After long negotiations, the traditional tenants are entitled as parties of the lease agreements and are paid directly another US \$1.40 per acre per year during the remainder of the lease period. In this way, the traditional tenants who acknowledge the lease will receive US \$3.20 per acre per year (Afdg [3]). Moreover, Addax promises to create 4000 jobs (2000 being permanent and 2000 being casual workers) during the development, construction and operation phase (United Nations Peace Building Commission [8]). This way, people who will lose their land will have a chance for an alternative income.

\subsection{Effectiveness and sufficiency of measure taken by Addax}

\subsubsection{Land and water sufficiency}

Even in the early stages of Addax undertaking, there have been complaints from the community on availability of land. According to SiLNoRF [9], two towns asked Addax to sign a MOU that would commit Addax to only use the demarcated land. Some households did not have the lease documents making it difficult to know what the demarcated land entailed which impedes on further use and investments of that land. Moreover, according to the Oakland Institute 
[10] who has been conducting interviews in the region some tenants have never met their legal representatives and most tenants had never seen the Land Lease Agreement at all, and are not familiar with the terms. In fact, several tenants claim that they did not know what land was to be leased or for how long when they signed the agreement and some are still unsure. As the local people are experiencing the results of the land lease agreement there is a growing dissatisfaction with the situation. Unfortunately, it is problematic knowing where to turn with these complaints since the actual terms of the land lease agreement presents a problem. For example according to Bread for All [11] it states that any disputes will have to be resolved in a tribunal in London, meaning landowners would have to go there to fight for their cause, which could be too costly for chiefdoms. This merely enhances the power inequality and suggests that once the contract has been signed there is no turning back.

The Oakland Institute [10] reported that the local people were complaining early on about losing their fertile rice producing lands to the Addax project. Fallow and cultivated lands were used contrary to Addax claims that the site selected for the project was previously degraded wasteland. Even agricultural officers who worked in the area before have refuted these claims. Many farmers especially women's groups earned their living from this area by cultivating rice, cassava, and vegetables and that the land was rich and fertile.

Identification of land availability was done using aerial photography. The 46370ha leased area south of Makeni highway was categorized according to land use (Afdb [12]). This provided key information on how the land may be altered for future use and how the current project layout affects the sufficiency of land available to the community. The area needed for cultivation and charcoal production is limited due to project land use objectives. In order to allow for project expansion within the area, alteration or intensification of the land is inevitable. It is likely that changes forwarding new land use objectives will impede on a supposed modifiable land area. It will also assume that the modifiable land is fit for alteration or that the farmers have the means to intensify agricultural production on the land that is left available.

According to Addax [12], the amount of people living within the leased area was estimated to 24000 people of whom 13617 were perceived as project affected people (PAPs). The PAPs are included in the FDP that aims to cultivate 1960ha of land in order to meet baseline needs. It was not clearly stated as to how or where this land would be acquired and at whose expense. This land is to supply each PAP with $100 \mathrm{~kg}$ of rice annually (Afdb [3]) which is merely half of the caloric needs for a reasonable food diet of 1809kcal/person/day (WFP [2]). According to FAO [13], the annual per capita consumption is estimated at $200 \mathrm{~kg} /$ person/year, which is double the amount of Addax baseline assumption. The rice would need to be supplemented with other sources of food to meet Addax baseline needs. The ESHIA does not state whether the FDP land can accommodate other sources of food. SiLNoRF monitoring report [9] has stated that the FDP has harvested close to 1600 tonnes of rice, which according to the community is overstated as they found the yields to be insufficient to meet food security needs. The Woreh Yeama community even reported that they were 
suffering from hunger due to the small FDP fields and the poor FDP harvest. One community had access to a fraction of the FDP land that was promised to them. This was due to a conflict of interest where other locals claimed usage of the land where the FDP community field was intended to be placed.

When it comes to water use, the main source of irrigation water for the Addax Bioenergy project will be from the Rokel River, Sierra Leone's biggest river. The Agreement between Addax and the Sierra Leonean government requires Addax to pay a negligible amount of 3 Leones (0.007 US cents) per cubic meter of water abstracted from the Rokel River. No mention is made of how much water the project intends to draw from the river for its irrigation or whether water extraction will be monitored. A report by WaterLex [7] points out a lack of guarantees to ensure local population's access to safe drinking water. Further, it also identifies risks for the mere access to sufficient water further downstream during the dry season. According to the report, the project will use $26 \%$ of the river flow during the driest months (February to April). Addax only claims to use an annual average of $2 \%$ water abstraction, a figure based on calculations during the wettest months of the year. Because no access has been given to any of the detailed studies Addax claim to have conducted, it is not clear what impacts such a high abstraction would have on fish stock and the local agriculture.

\subsubsection{Effectiveness of the FDP and the FFLS}

According to Addax, the FFLS has supported farmers in boosting agricultural skills (Afdb [3]). Bread for All [11] reported that project participants have made complaints on being equipped with theoretical and outlandish knowledge unfit for the local situation. The training that involves the use of modern agricultural tools and implements cannot be applied by locals who have never seen these tools and who cannot afford the inputs (fertilizers and other agrochemicals). As stated by Addax, the FDP inputs would be subsidized for three years and after that, all inputs would be made available for purchase. However, SiLNoRF [9] reported problems in accessing agricultural inputs due to the lack of money. One community even had to exchange rice for inputs ultimately impeding on food security.

\subsubsection{Alternative income sufficiency and compensation}

The leased land will be paid for, giving the project affected persons (PAPs) US\$12/hectare/year (3 cents hectare/day). According to Oakland Institute [10], many have decried the amount as too little in relation to the true value of the lands as well as the current price of rice at US\$1.7/ kg.While there has been legal representation for tenants in making the land lease agreement, these have been paid for by Addax and are therefore unlikely to act completely unbiased. The financial compensation is not in itself sufficient for a family to live on.

The WaterLex report [7] indicates that jobs have not materialized as promised. Addax promised 4000 jobs but according to an independent study in June 2011, interviews in the communities suggest that only 600 jobs have been created for people from Sierra Leone. Out of the people who actually were initially employed, many were fired after only three months due to the lack of skills and are now without job and land. Addax have responded to this 
accusation on their website saying that they expect to employ even more people when operations begin in 2013 which is yet to be seen.

\section{Discussion}

The study shows that Addax has tried to identify project impacts on food security and tried to mitigate them. However, the measures were poorly planned, risk prone, and do not appear to have succeeded in safe-guarding food supply. Addax's use of the ESHIA to identify impacts was commendable but it is evident that this identification process in itself was not complete. For example, the impact on food security due to potential loss of pastures, wild fruit collection, game hunting etc., were not mentioned anywhere in the ESHIA. Or the assertion that the land on which the project is to be implemented is a wasteland which is refuted by the communities. It can therefore be said that because of such loopholes, any mitigation measures proposed were based on obscure baseline data and are therefore insufficient.

The ESHIA shows that Addax prioritized employment opportunities and agricultural intensification as a way to mitigate negative impacts on food security. Although this undertaking has provided the community with jobs and skills, it has also had some profound consequences that remained unidentified in the impact assessment. The most recent monitoring report conducted by SiLNoRF [9] shows that the employment opportunities were exaggerated as were the FDP yield potentials and FFLS scheme setup. Community members left their livelihoods for employment that only lasted for a couple of months before they were let go which left them worse off than before. The money the people are receiving for leasing the land is small sum and far from a sufficient compensation in this situation.

The heavy reliance on agricultural intensification through improving agricultural knowledge and techniques of the locals has also been shown to be working unfavorably. The cultivation areas for food and charcoal will be heavily reliant on intensification inputs and equipment in order for the available land to be sufficient for all land use purposes. However, there is no information on whether the modifiable soil is fit enough for cultivation, as it is most likely in process of recovery. The only option to put the modifiable land to good use is through intensification that requires costly inputs and equipment. According to SiLNoRF [9], the local farmers find some of the skills they are being taught strange and incompatible with their old ways. Some of the machinery being proposed is expensive to purchase and maintain. Moreover, the subsidized input period has run out, and farmers are finding it hard to afford the modern agricultural inputs that are required for the intensification scheme. This also shows that the proposed measures are not consistent with the existing practices in the society. Generally, existing practices and traditions have been neglected in the process. It has to be understood that the issue is very complex and covers many more areas than can be discussed in this paper, such as the specific consequences that women suffer and the cultural value of land. After all, land is not only important for livelihood and ensuring food security. 
Similarly, the use of the ESHIA process alone cannot simply render the project "sustainable" and food secure as Addax has claimed in many of their documents. Some of the mitigation measures presented above are so vague and if not properly monitored can result in dire consequences for the communities and the entire region. This creates a reliance on monitoring and measurement, the capacity for which is clearly not available. If not adhered to, the communities are most likely to suffer the consequences of a precarious food security. An ESHIA is often an undertaking driven by laws but the process needs to be transparent beyond the review stage in order not to compromise future responsibility and accountability.

Lastly, there appears to be a lack of presence of the Sierra Leonean Government throughout this entire process. Firstly, the lack of clear laws and policies has left a void that was readily filled with other criteria that may not have related directly to the Sierra Leonean people. Also, the eagerness of the central government to attract investors has meant that the rights of the people take a back seat. For example, the price that Addax is paying for the land in Makeni, while deplorable, is supposedly the best so far in Sierra Leone (Addax website, Audio recording). This shows neglect on the side of the government and a lack of concern for the livelihoods of its people.

\section{Conclusions}

Food security is complex and involves a web of interconnected factors that must be solved in a holistic manner. The study shows that Addax tried to identify food security related impacts of the project locally and that of the region as well as mitigate them. However, they have not been entirely successful as shown by studies from civil society and other sources in the media. The reasons for this appear to stem mainly from weakness in governance that resulted in lax laws and regulations resulting in limited oversight. It is important to note that it is the role of government to ensure the food security of the citizens. The mitigation measures implemented by Addax were proposed based on insufficient baseline data and cannot therefore be expected to be wholly appropriate or sufficient.

The measures taken have provided some usefulness in adapting farming towards more skillful intensified agriculture that the community may use beyond the FDP. And overall, the production of biofuels may present future opportunities for the region to become less dependent on a volatile energy and fuel market. However, the shortcomings are likely to leave the communities exposed to risks and shocks that threaten the overall food stability and hence food security. It is therefore recommended that impact studies should be much more thorough, and base on appropriate information other than what suits project owners as these are likely to have repercussions in the future. In this regard, the role of governments for making and enforcing appropriate laws and regulations that protect rights of people and the environment is crucial. The need for oversight must not be overlooked as large corporations are mainly interested in financial gain and may not have any regard for communities in areas inherently deficient in oversight and week implementation of laws. Benefits for both 
investors and communities can only become reality if designs of projects, such as the Addax Bioenergy project, are more holistic. Measures to mitigate impacts need to be tailored to the community's needs and it may be wise to implement these projects in stages that allow communities sufficient time to absorb changes and appropriately adjust in the way they know how.

\section{References}

[1] World Watch Institute (WWI). Biofuels for transport: global potential and implications for sustainable energy and agriculture, London; Sterling, VA: Earth scan, 2007.

[2] World Food Programme (WFP). The state of food security and nutrition is Sierra Leone 2011, 2011. Available at: http://www.wfp.org/

[3] African Development Bank. (Afdb) Executive Summary of the Comprehensive Resettlement Policy Framework and the Pilot Phase Resettlement Action Plan. 2012. Available at: http://www.afdb.org /en/documents/

[4] The World Health Organization. Internet source: http://www.who.int /trade/glossary/story028/en/ (accessed 2012).

[5] FAO. Food security Policy Brief, 2012. Available at: ftp://ftp.fao.org /es/esa/policybriefs/pb_02.pdf

[6] Dauber, J. Brown, C. Fernando AL. Finnan, J. Krasuska, E. Ponitka, J. Styles, D. Thrän, D. Van Groenigen, KJ. Weih, M. Zah, R. Bioenergy from "surplus" land: environmental and socio-economic implications, 2012. Available at: http://www.pensoft.net/J_FILES/2/articles/3036/3036-G-1layout.pdf

[7] WaterLex. Independent study report of the Addax Bioenergy Sugarcane-ToEthanol Project in the Makeni region in Sierra Leone, 2011. Available at: http://www.brotfueralle.ch

[8] United Nations Peace Building Commission. Supporting the government of Sierra Leone and its international partners to generate employment for the youth, 2011. Available at: http://www.un.org/en/peacebuilding/cscs/sl /key_docs/sl_youth_employment14feb2011.pdf

[9] Sierra Leone Network on the Right to Food (SiLNoRF). Annual Monitoring Report on the Operations of Addax Bioenergy for the period June 2011June 2012, 2012.

[10] The Oakland Institute. Understanding Land Investment Deals in Africa: Sierra Leone Country Report, 2011. Available at: http://www.oaklandinstitute.org /sites/oaklandinstitute.org/

[11] Bread for all. Concerns of civil society organizations and affected land users on Addax Bioenergy. 2012. Available at: http://www.brotfueralle.ch/

[12] African Development Bank. Addax Bioenergy Project - ESHIA, 2012. Available at: http://www.afdb.org/en/projects-and-operations/

[13] FAO. Rice is life: International year of rice 2004. Internet source: http://www.fao.org/rice2004/en/p18.htm (accessed 2012). 